\title{
Sex Differences in the Genetic and Environmental Influences on Childhood Conduct Disorder and Adult Antisocial Behavior
}

\author{
Madeline H. Meier and Wendy S. Slutske \\ University of Missouri-Columbia
}

\author{
Andrew C. Heath \\ Washington University School of Medicine
}

Nicholas G. Martin

Queensland Institute of Medical Research

\begin{abstract}
Sex differences in the genetic and environmental influences on childhood conduct disorder and adult antisocial behavior were examined in a large community sample of 6,383 adult male, female, and opposite-sex twins. Retrospective reports of childhood conduct disorder (prior to 18 years of age) were obtained when participants were approximately 30 years old, and lifetime reports of adult antisocial behavior (antisocial behavior after 17 years of age) were obtained 8 years later. Results revealed that either the genetic or the shared environmental factors influencing childhood conduct disorder differed for males and females (i.e., a qualitative sex difference), but by adulthood, these sex-specific influences on antisocial behavior were no longer apparent. Further, genetic and environmental influences accounted for proportionally the same amount of variance in antisocial behavior for males and females in childhood and adulthood (i.e., there were no quantitative sex differences). Additionally, the stability of antisocial behavior from childhood to adulthood was slightly greater for males than females. Though familial factors accounted for more of the stability of antisocial behavior for males than females, genetic factors accounted for the majority of the covariation between childhood conduct disorder and adult antisocial behavior for both sexes. The genetic influences on adult antisocial behavior overlapped completely with the genetic influences on childhood conduct disorder for both males and females. Implications for future twin and molecular genetic studies are discussed.
\end{abstract}

Keywords: sex differences, conduct disorder, antisocial behavior, development, heritability

Antisocial behavior (i.e., delinquency, criminality, aggression, conduct disorder, and antisocial personality disorder) is a prevalent problem in the United States and a source of significant burden to its citizens both socially and economically (Anderson, 1999). Despite progress in understanding the etiology of antisocial behavior, research has failed to unveil the mechanisms underlying one of the most basic and robust risk factors for antisocial behavior: the male sex.

Males are more likely than females to engage in antisocial behavior at every stage in life (Moffitt, Caspi, Rutter, \& Silva,

This article was published Online First January 10, 2011.

Madeline H. Meier and Wendy S. Slutske, Department of Psychological Sciences and Midwest Alcoholism Research Center, University of MissouriColumbia; Andrew C. Heath, Washington University School of Medicine; Nicholas G. Martin, Queensland Institute of Medical Research, Brisbane, Australia.

Madeline H. Meier is now at Department of Psychology and Neuroscience, Duke University.

Data collection for this study was funded by National Institutes of Health Grants AA010249 and MH66206. Preparation of this article was supported in part by National Institute of Mental Health Grant F31MH079683. The content is solely the responsibility of the authors and does not necessarily represent the official views of the National Institute of Mental Health.

Correspondence concerning this article should be addressed to Madeline H. Meier, who is now at 2020 West Main Street, Suite 201, Box 104410, Durham, NC 27708. E-mail: Madeline.Meier@duke.edu
2001). This sex difference suggests that a large etiological component of antisocial behavior consists of factors associated with the male sex-factors that are biological or psychosocial in origin or both. For example, there may be sex-specific genes influencing antisocial behavior or causative environmental circumstances that only arise for males. Alternatively, males and females may share all of the same risk factors for antisocial behavior, but these risk factors are, for some reason, more prevalent among males and/or males are more vulnerable to them (Moffitt et al., 2001; Rowe, Vazsonyi, \& Flannery, 1995).

In general, the correlates of antisocial behavior seem to be the same for males and females (Moffitt et al., 2001; Rowe et al., 1995). For example, Moffitt et al. (2001) reported that there were no replicable sex-specific risk factors for antisocial behavior across a broad array of risk predictors in the Dunedin study. These findings suggest that it is unlikely that the risk factors for antisocial behavior are different for males and females. However, the general consensus that risk factors for antisocial behavior are more similar than different for males and females is based largely on studies that cannot evaluate the possibility of sex-specific genetic influences on antisocial behavior.

A number of twin studies have examined the possibility that the genetic factors influencing antisocial behavior differ for males and females (i.e., qualitative sex differences). In two studies, there was evidence for sex-specific genetic influences on antisocial behavior (Derks, Dolan, Hudziak, Neale, \& Boomsma, 2007; Rose, Dick, 
Viken, Pulkkinen, \& Kaprio, 2004). In two other studies (Eley, Lichtenstein, \& Stevenson, 1999; Vierikko, Pulkkinen, Kaprio, Viken, \& Rose, 2003), evidence of sex-specific influences on antisocial behavior emerged, but it was difficult to determine whether these sex differences were attributable to different genetic factors or different types of shared environmental influences for males and females. Although several other genetically informative studies have found no evidence of sex-specific influences on antisocial behavior (Eaves et al., 1997; Jacobson, Prescott, \& Kendler, 2002; Saudino, Ronald, \& Plomin, 2005; Slutske et al., 1997; Tuvblad, Eley, \& Lichtenstein, 2005; Van Hulle, Rodgers, D'Onofrio, Waldman, \& Lahey, 2007), the inconsistent findings across these studies highlight the possibility that at least some of the genes influencing antisocial behavior are different for males and females, and these genetic differences could account for the higher prevalence of antisocial behavior among males.

Alternatively, males and females may share all of the same genetic and environmental risk factors for antisocial behavior, but these risk factors may impinge more on one sex than the other. If the genetic or shared environmental influences accounted for proportionally more variance in antisocial behavior for males than females, this may (though not necessarily; see Rutter, Caspi, \& Moffitt, 2003) suggest that males are more vulnerable to risk for antisocial behavior and explain why rates of antisocial behavior are higher among males. Results have been mixed regarding sex differences in the magnitude of genetic and environmental influences on antisocial behavior (i.e., quantitative sex differences). Whereas some twin and adoption studies have not found sex differences in the magnitude of genetic and environmental contributions to antisocial behavior (e.g., Eaves et al., 1997; Gelhorn et al., 2005; Rhee \& Waldman, 2002; Slutske et al., 1997; Taylor, McGue, \& Iacono, 2000), others have found such differences (e.g., Bartels et al., 2003; Eley et al., 1999; Jacobson et al., 2002; Miles \& Carey, 1997; Rose et al., 2004; Saudino et al., 2005; Tuvblad et al., 2005). Of the studies that have found evidence of sex differences in the magnitude of genetic and environmental influences on antisocial behavior, the direction of the reported sex difference is inconsistent across studies, with nearly equal numbers of studies reporting that antisocial behavior was more heritable for girls than boys (e.g., Eley et al., 1999; Jacobson et al., 2002; Rose et al., 2004; Tuvblad et al., 2005; Vierikko et al., 2003) as studies reporting that antisocial behavior was more heritable for boys than girls (e.g., Bartels et al., 2003; Miles \& Carey, 1997; Saudino et al., 2005; Silberg et al., 1994; Stevenson \& Graham, 1988; van den Oord, Boomsma, \& Verhulst, 1994).

One potential explanation for the inconsistent findings regarding qualitative and quantitative sex differences across studies is that these sex differences vary with age. For example, the specific genes or shared environmental factors influencing antisocial behavior may change across development, and these developmental changes may vary with sex. Furthermore, it is fairly well established that the genetic and environmental architecture of antisocial behavior changes across development, with shared environmental factors accounting for relatively more variance in child antisocial behavior and genetic factors accounting for relatively more variance in adult antisocial behavior (Lyons et al., 1995; Jacobson et al., 2002). It is quite possible that the developmentally based changes in the relative influences of genes and shared environment on antisocial behavior differ for males and females.
Only a handful of studies have examined sex differences in the genetic and environmental influences on antisocial behavior across development. Tuvblad et al. (2005) examined sex differences in the genetic and environmental influences on parent-reported and subsequently self-reported delinquent behavior for twins assessed at age 8 and again at age 13. At age 8, there was evidence of both qualitative and quantitative sex differences: either the genetic or the shared environmental factors contributing to delinquent behavior were different for boys and girls, and genetic influences on delinquent behavior were greater for girls, whereas shared environmental influences were greater for boys (this result was first published in a previous analysis of these data by Eley et al., 1999). By age 13, however, there was no evidence of a qualitative genetic or shared environmental sex difference, but the heritability of delinquent behavior remained greater among girls, and shared environmental influences remained greater among boys. In addition, there were sex differences in the sources of the continuity of delinquent behavior from ages 8 to 13 . For boys, shared environmental influences accounted for the majority of the stability of delinquent behavior across development, whereas genetic factors completely accounted for the stability of delinquent behavior among girls. As another example, Hicks et al. (2007) found no evidence of sex differences in the magnitude of genetic and environmental influences on adult antisocial behavior in a longitudinal sample of twins ages 17 to 24 years (qualitative sex differences were not examined in this study, as the sample did not include opposite-sex twin pairs).

The only twin study to examine both quantitative and qualitative sex differences in the genetic and environmental influences on antisocial behavior from childhood through adulthood was a study by Jacobson, Prescott, and Kendler (2002). In this study, adult twins reported on the antisocial behavior in which they had engaged as children (before 15 years of age), adolescents (ages 15-17), and adults (after age 17). There was no evidence of sex-specific genetic or shared environmental influences on antisocial behavior at any point in development. However, sex differences in the magnitude of genetic and environmental influences on childhood antisocial behavior emerged, with stronger genetic influences found for females and stronger shared environmental influences found for males. As expected, heritability increased and shared environmental influences decreased from childhood to adolescence and adulthood for both males and females, but this pattern was more pronounced for males, resulting in almost no sex differences in the magnitude of genetic and environmental influences on adolescent and adult antisocial behavior. Jacobson et al. suggested that later pubertal onset among males compared to females might explain the finding that the estimates of heritability for males caught up to those for females by late adolescence.

The aim of the present study was to examine sex differences in the genetic and environmental influences on childhood conduct disorder and adult antisocial behavior in a large sample of same- and opposite-sex twins from the general population. This study represents only the second study to examine both qualitative and quantitative sex differences in the genetic and environmental influences on antisocial behavior from childhood to adulthood. 
Method

\section{Participants}

Participants were members of the national Australian Twin Registry. Details concerning participant recruitment are reported elsewhere (Lynskey et al., 2002; Slutske et al., 2009). In 19962000, members of the Australian Twin Registry born between 1964 and 1971 were contacted to participate in a study involving a telephone administration of a structured psychiatric interview in which childhood conduct disorder was assessed. The participation rate for this interview was $84.2 \%$, with a total of $N=6,265$ individuals participating. There was no evidence that participants and nonparticipants in this interview differed in terms of their levels of childhood conduct disorder symptomatology. ${ }^{1}$ Of the 6,265 twins who participated in the 1996-2000 interview, 2\% ( $n=109)$ were excluded from the current analyses because of missing data. At the time of this interview, the twins were between 24 and 36 years of age $(M=29.94, S D=2.44)$.

Members of the Australian Twin Registry who were born between 1964 and 1971 were contacted again between 2004 and 2007 (or an average of 8 years after the 1996-2000 interview) to participate in another structured telephone interview in which adult antisocial behavior was assessed. The participation rate for this 2004-2007 interview was $80.4 \%$ (Slutske et al., 2009). There was some evidence that individuals with a history of childhood conduct disorder were less likely to participate in this interview than those without such a history, although the net effect of this differential attrition was small (see Slutske et al., 2009 for details). A total of $N=4,764$ individuals participated in the 2004-2007 interview. Of the 4,764 twins who participated in this interview, 17 twins were excluded from the current analyses because of missing data. At the time of this 2004-2007 interview, the twins were between 32 and 43 years of age $(M=37.66, S D=2.30)$.

Combining participants from both interviews yielded a total sample size of 6,383 twins, of which 4,520 twins (71\%) completed both the 1996-2000 and the 2004-2007 interviews. The majority (73\%) of twins who completed the 1996-2000 interview also completed the 2004-2007 interview, and almost all (95\%) of the twins who completed the 2004-2007 interview also completed the 1996-2000 interview. The sample consisted of 1,502 monozygotic female twins; 1,135 monozygotic male twins; 1,183 dizygotic female twins; 991 dizygotic male twins; and 1,572 dizygotic opposite-sex twins.

\section{Measures}

Zygosity. Information on twin zygosity was ascertained with a self-report questionnaire assessing twins' physical similarity and the frequency with which the twins were mistaken for each other as children. The questionnaire method of determining twin zygosity has been found to be $95 \%$ accurate (Eaves, Eysenck, \& Martin, 1989). We were able to assess the accuracy of our zygosity assignments for the current study on account of the availability of DNA for 241 of the same-sex twin pairs. The error rate for zygosity determination, based on 241 same-sex twin pairs in the current sample, was 2.5\% (Slutske et al., 2009).

Childhood conduct disorder. Participants completed the Semi-Structured Assessment for the Genetics of Alcoholism
(Bucholz et al., 1994), which includes a diagnostic assessment of conduct disorder based on the criteria in the Diagnostic and Statistical Manual of Mental Disorders (4th ed. [DSM-IV]; American Psychiatric Association, 1994). Participants retrospectively reported on the 15 symptoms of conduct disorder that they had experienced before age $18,{ }^{2}$ and each symptom was assessed for both seriousness and pervasiveness. The 15 conduct disorder symptoms were summed to create a scale indexing the number of symptoms participants experienced before 18 years of age. A sample of 215 participants from the 1996-2000 study was randomly selected for retest 4 years after the main assessment. ${ }^{3}$ The 4-year test-retest reliability for the childhood conduct disorder scale was $r=.75$ (Pearson correlation coefficient), and this test-retest reliability did not differ significantly across sexes, $t(214)=-0.25, p=.80$.

Adult antisocial behavior. Approximately 8 years after participants reported on their childhood conduct disorder symptoms, they were asked to report on their adult antisocial behavior, that is, antisocial behavior in which they had engaged since turning 18 years old. The measure of antisocial behavior we used was based on the measure of adult antisocial behavior used by Jacobson et al. (2002). However, whereas Jacobson et al. assessed childhood conduct disorder and adult antisocial behavior with self-report questionnaires, we collected these data using structured diagnostic telephone interview. Participants were asked to report on the frequency with which they had engaged in 17 specific behaviorsbehaviors that correspond to the seven adult criteria for DSM-IV antisocial personality disorder (these items can be found in Kendler \& Prescott, 2006, pp. 83-84). The response options for each of the 17 behaviors were: never, 1-2 times, 3-5 times, and 6 or more times. A computer algorithm was used to combine the responses for each of the 17 behaviors into a 7-item scale. Each of the seven adult antisocial personality disorder criteria was considered present if the sum of the frequency of the behaviors indexing it was greater than or equal to 3 (i.e., often). A subsample of 166 participants from the 2004-2007 study was selected for a retest

\footnotetext{
${ }^{1}$ Potential sample bias was examined by comparing mean levels of childhood conduct disorder for twins who were concordant (i.e., complete twin pairs) versus discordant (i.e., incomplete twin pairs) for participation. Assuming that levels of conduct disorder are correlated for twins within a pair, if twins from incomplete twin pairs had higher levels of conduct disorder, this would suggest that nonparticipants were more likely to have higher levels of conduct disorder than participants. However, there was no difference in logged conduct disorder scores for females from complete $(M=0.22, S D=0.42)$ versus incomplete twin pairs $(M=0.21, S D=$ $0.42), t(2601)=-0.37, p=.71$, or for males from complete $(M=0.58$, $S D=0.62)$ versus incomplete twin pairs $(M=0.61, S D=0.63)$, $t(2042)=0.94, p=.35$.

${ }^{2}$ As a check for potential bias introduced by retrospective reports, we obtained the correlation between age at the time of the conduct disorder interview and the number of reported conduct disorder symptoms. This correlation was -.02 , indicating that participants with longer lengths of recall reported a similar number of childhood conduct disorder symptoms as did participants with shorter recall lengths.

${ }^{3}$ Individuals randomly selected for retest reported slightly more childhood conduct disorder symptoms $(M=0.99, S D=1.49)$ than did individuals who were not selected to participate in the retest study $(M=0.78$, $S D=1.36), t(6218)=2.20, p=.03, d=0.15$.
} 
study approximately 3 months after the main assessment. ${ }^{4}$ The 3-month test-retest reliability for the seven-item adult antisocial behavior scale was $r=.75$ (Pearson correlation coefficient), and there were no sex differences in the test-retest reliability of adult antisocial behavior, $t(164)=-0.75, p=.46$.

Environmental similarity. Twin similarity of childhood and adult environments was assessed during the 1996-2000 interview. Twin similarity of childhood environment was measured with four items: frequency of sharing the same friends, dressing alike, being in the same classes in primary school, and being in the same classes in high school. Responses to each item were averaged across twins within a pair and then summed to form a composite scale, with higher scores indicating greater similarity of environment. Twin similarity of adult environment was measured with two items assessing frequency of seeing each other and frequency of contacting each other by telephone, e-mail, letter, or fax. Responses to these two items were also averaged across twins within a pair and summed to form a composite scale, with higher scores indicating greater contact.

\section{Data Analysis}

Estimates of the genetic and environmental influences on childhood conduct disorder and adult antisocial behavior were obtained with standard univariate twin models (Neale \& Cardon, 1992). The twin design is based on the premise that differences in resemblance between monozygotic twin pairs, who share $100 \%$ of their genes, and dizygotic twin pairs, who share approximately $50 \%$ of their segregating genes, can be used to parse variance in a trait into additive genetic (A), shared environmental (C), and nonshared environmental influences (E). Several assumptions underlie the twin model, namely, that (a) monozygotic and dizygotic twins are equally correlated in their exposure to trait-relevant environments (i.e., the equal environments assumption), (b) there is no assortative mating for the trait, and (c) there are no gene-environment correlations or interactions for the trait (see Rijsdijk \& Sham, 2002).

Standard univariate twin models were extended to test for quantitative and qualitative sex differences in the genetic and environmental influences on childhood conduct disorder and adult antisocial behavior. Quantitative sex differences refer to sex differences in the magnitude of genetic, shared environmental, and nonshared environmental influences (Figure 1: $\mathrm{a}_{\mathrm{m}} \neq \mathrm{a}_{\mathrm{f}}, \mathrm{c}_{\mathrm{m}} \neq \mathrm{c}_{\mathrm{f}}, \mathrm{e}_{\mathrm{m}} \neq \mathrm{e}_{\mathrm{f}}$ ), whereas qualitative sex differences refer to sex differences in the actual genetic or shared environmental factors influencing the phenotype. Qualitative genetic sex differences are apparent when the genetic correlation (Figure 1: $r \mathrm{~A}$ ) among opposite-sex twin pairs is estimated to be less than .50-the expected correlation for dizygotic twin pairs given their genetic relatedness. Thus, a genetic correlation of less than .50 among opposite-sex twin pairs would suggest that different genetic factors are operating for males and females. Qualitative shared environmental sex differences are apparent when the shared environmental correlation (Figure 1: $r \mathrm{C}$ ) among opposite-sex twin pairs is estimated to be less than $1.00-$ the expected correlation for monozygotic and same-sex dizygotic twins. Thus, a shared environmental correlation among oppositesex twin pairs of less than 1.00 would suggest that opposite-sex twins have fewer shared environmental experiences than same-sex twins.
Three univariate sex-limitation models were fit to the data for childhood conduct disorder and adult antisocial behavior, considered individually. The first model was the full sex-limitation model, which allows for both quantitative and qualitative sex differences as well as sex differences in phenotypic variances. In this model, seven parameters were estimated (Figure 1: $a_{m}, c_{m}, e_{m}$, $\mathrm{a}_{\mathrm{f}}, \mathrm{c}_{\mathrm{f}}$, and $\mathrm{e}_{\mathrm{f}}$ and either $r \mathrm{~A}$ or $r \mathrm{C}$ ). Because a model estimating both $r \mathrm{~A}$ and $r \mathrm{C}$ simultaneously is not identified, these correlations were estimated separately in two different, non-nested models. The fits of these two non-nested models, that is, a model estimating $r \mathrm{~A}$ versus a model estimating $r \mathrm{C}$, were compared with the Akaike information criterion (AIC), and the model with the smaller AIC was selected as the best fitting model. The second model was the common effects model, which differs from the full sex-limitation model only in that parameters $r \mathrm{~A}$ and $r \mathrm{C}$ were fixed to .50 and 1.00 , respectively. Thus, the common effects model allows for quantitative sex differences as well as sex differences in phenotypic variances but not qualitative sex differences. The third model was the scalar model, which allows for sex differences only in phenotypic variances (i.e., no qualitative or quantitative sex differences). In this model, estimates for genetic, shared environmental, and nonshared environmental influences are constrained to be proportionally equal for males and females. The full sex-limitation model, the common effects model, and the scalar model are hierarchically related (i.e., the scalar and common models are nested within the full model, and the scalar model is nested within the common model) and were compared with chi-square difference tests and AIC to determine the better fitting model.

After fitting the univariate sex-limitation models for both childhood conduct disorder and adult antisocial behavior considered individually, bivariate Cholesky models of childhood conduct disorder and adult antisocial behavior were fit to the data to determine the extent to which the covariation between these traits was due to genetic, shared environmental, and nonshared environmental influences. Because the results of the univariate sex-limitation models of childhood conduct disorder were suggestive of qualitative sex differences, bivariate models of childhood conduct disorder and adult antisocial behavior were fitted for males and females separately. Thus, opposite-sex twins were not included in the bivariate analyses.

All analyses were conducted in Mplus (Muthén \& Muthén, 1998-2007) with maximum likelihood estimation. Mplus allows for the estimation of models with missing data under missing completely at random and missing at random conditions. Thus, twins from complete and incomplete twin pairs as well as twins who had completed one or both of the two interviews were included in all analyses.

\footnotetext{
${ }^{4}$ Participants with gambling problems were oversampled for the retest study, as the retest study was part of a larger study focused on pathological gambling (Slutske et al., 2009). Thus, individuals who participated in the retest study also reported more lifetime adult antisocial behavior symptoms $(M=1.32, S D=1.49)$ than individuals who were not selected to participate in the retest study $(M=0.72, S D=1.15), t(4745)=6.48, p<$ $.001, d=0.45$.
} 


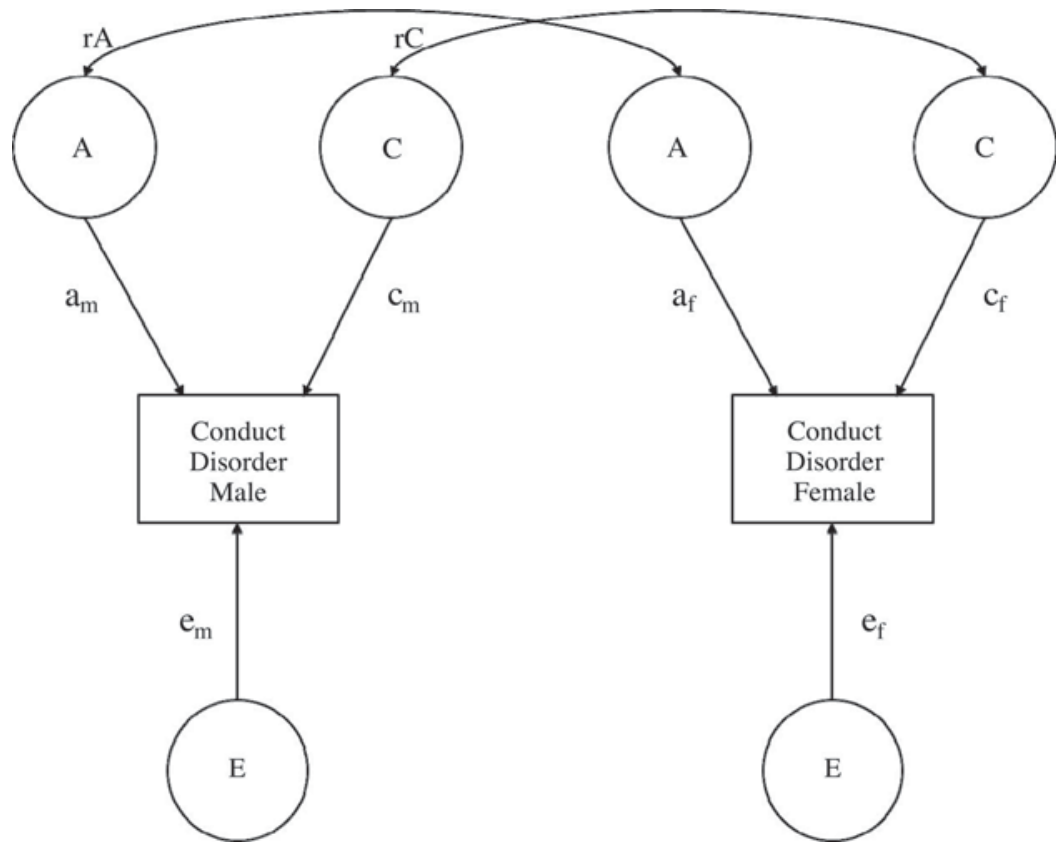

Figure 1. Univariate sex-limitation model for childhood conduct disorder. The magnitude of additive genetic (A), shared environmental (C), and nonshared environmental (E) influences may differ for males and females $\left(\mathrm{a}_{\mathrm{m}} \neq \mathrm{a}_{\mathrm{f}}, \mathrm{c}_{\mathrm{m}} \neq \mathrm{c}_{\mathrm{f}}, \mathrm{e}_{\mathrm{f}} \neq \mathrm{e}_{\mathrm{m}}\right)$, and/or the genetic $(r \mathrm{~A})$ or shared environmental $(r \mathrm{C})$ correlation among opposite-sex twins may fall below the expected genetic (.50) and shared environmental (1.00) correlations for same-sex dizygotic twins. The same univariate sex-limitation model was used for adult antisocial behavior.

\section{Results}

\section{Descriptive Statistics}

Approximately $4 \%$ of females and $18 \%$ of males met lifetime criteria for childhood conduct disorder, and approximately $4 \%$ of females and $16 \%$ of males met lifetime criteria for adult antisocial behavior. These prevalences of childhood conduct disorder and adult antisocial behavior are consistent with prevalence estimates reported in previous studies. ${ }^{5}$ Means and standard deviations for the symptom counts of childhood conduct disorder and adult antisocial behavior are presented in Table 1. Measures of childhood conduct disorder and adult antisocial behavior demonstrated significant positive skew, and a log transformation was performed prior to the genetic analyses in order to improve the normality of these measures. The skew of the childhood conduct disorder symptom count was 2.52 and 1.16 before and after the log transformation, respectively, and the skew of the adult antisocial behavior symptom count was 1.89 and 0.99 , respectively, before and after the $\log$ transformation.

Sex differences in the means and variances of these logtransformed variables were examined in a series of three models of childhood conduct disorder and adult antisocial behavior separately. In the first set of models, the means and variances for childhood conduct disorder and adult antisocial behavior were constrained to be equal across sex: for childhood conduct disorder, $\chi^{2}(23)=1,516.47$, and for adult antisocial behavior, $\chi^{2}(23)=$ 811.80. Next, the variances for childhood conduct disorder and adult antisocial behavior were freely estimated for each sex, which resulted in a significant improvement in model fit for both child- hood conduct disorder and adult antisocial behavior: for childhood conduct disorder, $\Delta \chi^{2}(1)=510.21, p<.05$, and for adult antisocial behavior, $\Delta \chi^{2}(1)=237.36, p<.05$. In the third and final set of models, both the means and the variances for childhood conduct disorder and adult antisocial behavior were freely estimated for each sex, and this model also resulted in a significant improvement in model fit: for childhood conduct disorder, $\Delta \chi^{2}(2)=1165.40, p<.05$, and for adult antisocial behavior, $\Delta \chi^{2}(2)=642.58, p<.05$, indicating that the means and variances for childhood conduct disorder and adult antisocial behavior were larger for males than females. Thus, in all sex-limited biometric models, the means and variances for childhood conduct disorder and adult antisocial behavior were allowed to vary across sex. It was because of the sex differences in phenotypic variances that a model testing exact equality (often referred to as an equality or null model) of genetic, shared environmental, and nonshared environmental estimates for males and females was not considered.

${ }^{5}$ The prevalence of childhood conduct disorder in our sample is consistent with the prevalence estimates reported in other studies (e.g., Gelhorn et al., 2005; Kendler \& Prescott, 2006; Rose et al., 2004; Slutske et al., 1997). Further, the prevalence of adult antisocial behavior in our sample falls within the range of estimates reported by studies with similar operationalizations of adult antisocial behavior. For example, the lifetime prevalence of adult antisocial behavior was $2.4 \%$ for females and $8.3 \%$ for males in the Jacobson et al. (2002) sample (as reported by Kendler \& Prescott, 2006), and the prevalence of adult antisocial behavior was $8.5 \%$ for females and $16.5 \%$ for males in the National Epidemiological Survey on Alcohol and Related Conditions (Compton, Conway, Stinson, Colliver, \& Grant, 2005). 
Table 1

Means and Standard Deviations of Childhood Conduct Disorder and Adult Antisocial Behavior Symptom Counts by Sex and Zygosity

\begin{tabular}{|c|c|c|c|c|c|c|c|c|}
\hline \multirow[b]{3}{*}{ Group } & \multicolumn{4}{|c|}{ Childhood conduct disorder } & \multicolumn{4}{|c|}{ Adult antisocial behavior } \\
\hline & \multicolumn{2}{|c|}{ Male } & \multicolumn{2}{|c|}{ Female } & \multicolumn{2}{|c|}{ Male } & \multicolumn{2}{|c|}{ Female } \\
\hline & $M$ & $S D$ & $M$ & $S D$ & $M$ & $S D$ & $M$ & $S D$ \\
\hline Monozygotic & 1.13 & 1.57 & 0.39 & 0.89 & 1.02 & 1.33 & 0.45 & 0.88 \\
\hline Same-sex dizygotic & 1.31 & 1.72 & 0.39 & 0.88 & 1.15 & 1.36 & 0.39 & 0.79 \\
\hline Opposite-sex dizygotic & 1.34 & 1.63 & 0.48 & 1.02 & 1.30 & 1.46 & 0.54 & 1.01 \\
\hline
\end{tabular}

\section{Twin Correlations}

Univariate and bivariate twin correlations for the childhood conduct disorder and adult antisocial behavior symptom counts and the results of tests of differences between correlations are presented in Table 2. For both childhood conduct disorder and adult antisocial behavior, the monozygotic twin correlations were significantly larger than the dizygotic twin correlations: for childhood conduct disorder, $\Delta \chi^{2}(1)=13.46, p<.001$, and for adult antisocial behavior, $\Delta \chi^{2}(1)=14.12, p<.001$, indicating the influence of genetic factors.

The male twin correlations for childhood conduct disorder and adult antisocial behavior were larger than the associated female twin correlations: for childhood conduct disorder, $\Delta \chi^{2}(1)=44.32$, $p<.001$, and for adult antisocial behavior, $\Delta \chi^{2}(1)=15.92, p<$ .001 , suggesting the possibility of sex differences in the magnitude of genetic and environmental influences on both childhood conduct disorder and adult antisocial behavior (quantitative sex differences). There was also evidence of a qualitative sex difference for childhood conduct disorder, as the opposite-sex twin correlation for childhood conduct disorder was statistically significantly smaller than the same-sex dizygotic twin correlations, $\Delta \chi^{2}(1)=$ $8.49, p<.01$. Though the opposite-sex twin correlation for adult antisocial behavior was smaller than the same-sex dizygotic twin correlations, this difference was not statistically significant, $\Delta \chi^{2}(1)=2.27, p=.13$.

The cross-twin, cross-trait correlations were larger for monozygotic than dizygotic twins, $\Delta \chi^{2}(1)=23.83, p<.001$, indicating the influence of genetic factors on the stability of antisocial behavior. Further, the stability of antisocial behavior was greater for males than females, as evidenced by the larger within-twin, crosstrait correlations for males compared to females, $\Delta \chi^{2}(1)=61.45$, $p<.001$. There was also evidence that the magnitude of the genetic and environmental influences on the stability of antisocial behavior differed across sex, as the cross-twin, cross-trait correlations were larger for males than females, $\Delta \chi^{2}(1)=34.41, p<$ .001. The cross-twin, cross-trait correlations were smaller for opposite-sex compared to same-sex dizygotic twins, $\Delta \chi^{2}(1)=$ $4.92, p<.05$, indicating a qualitative sex difference in the sources of the stability of antisocial behavior.

\section{Univariate Model Results}

Childhood conduct disorder. The model-fitting results and squared standardized path coefficients for childhood conduct disorder are presented in Table 3. Both full sex-limitation models (Table 3: full $r \mathrm{~A}$ and full $r \mathrm{C}$ ) fit better than the common effects model and the scalar model. The results of the full sex-limitation models indicated that either the genetic or the shared environmental factors influencing childhood conduct disorder were different for males and females. Further, though the magnitude of genetic, shared environmental, and nonshared environmental influences on childhood conduct disorder was allowed to differ for males and females in both full sex-limitation models, the proportion of variance in childhood conduct disorder accounted for by genetic, shared environmental, and nonshared environmental influences was quite similar for males and females. The parameter estimates for genetic, shared environmental, and nonshared environmental influences could be constrained to be proportionally equal across sex in both full models without a resultant deterioration in model fit: full $r \mathrm{~A}, \Delta \chi^{2}(2)=2.13, p=.34$; full $r \mathrm{C}, \Delta \chi^{2}(2)=2.04, p=$ .36 (results not shown in Table 3 ).

In summary, the results of the univariate model fitting suggested that there were qualitative sex differences in the genetic or shared environmental influences on childhood conduct disorder but no quantitative sex differences. Whether these qualitative sex differences were attributable to sex-specific genetic influences (full $r \mathrm{~A}$ ) or sex-specific shared environmental influences (full $r \mathrm{C}$ ) was difficult to resolve. In the full $r \mathrm{~A}$ model, the genetic correlation among opposite-sex twin pairs was initially estimated to be negative, likely because of insufficient covariance information in the data. This estimate was then constrained to be positive, resulting in the parameter being fixed at the lower bound $(r=0)$ of plausible values. In the full $r \mathrm{C}$ model, the shared environmental correlation among opposite-sex twin pairs was estimated to be $r=.23$, which can be compared to the expected correlation, given no qualitative shared environmental sex difference, of 1.00. The full $r \mathrm{C}$ model was selected as the best fitting model as a result of its slightly smaller AIC compared to the full $r$ A model. Notably, estimates for genetic, shared environmental, and nonshared environmental influences obtained from the full $r \mathrm{C}$ model matched the estimates obtained from separate models of each sex (results not shown).

Adult antisocial behavior. The results of the univariate model fitting for adult antisocial behavior are presented in Table 3. A full sex-limitation model allowing for sex-specific shared environmental influences was not fitted, as results from both the full $r \mathrm{~A}$ model as well as separate models of adult antisocial behavior for each sex (not shown) indicated no effect of shared environment for females and a small, nonsignificant effect of shared environment for males. The best fitting model was the scalar model, which indicated that genetic and environmental influences accounted for proportionally the same amount of variance in adult antisocial behavior for males and females. 

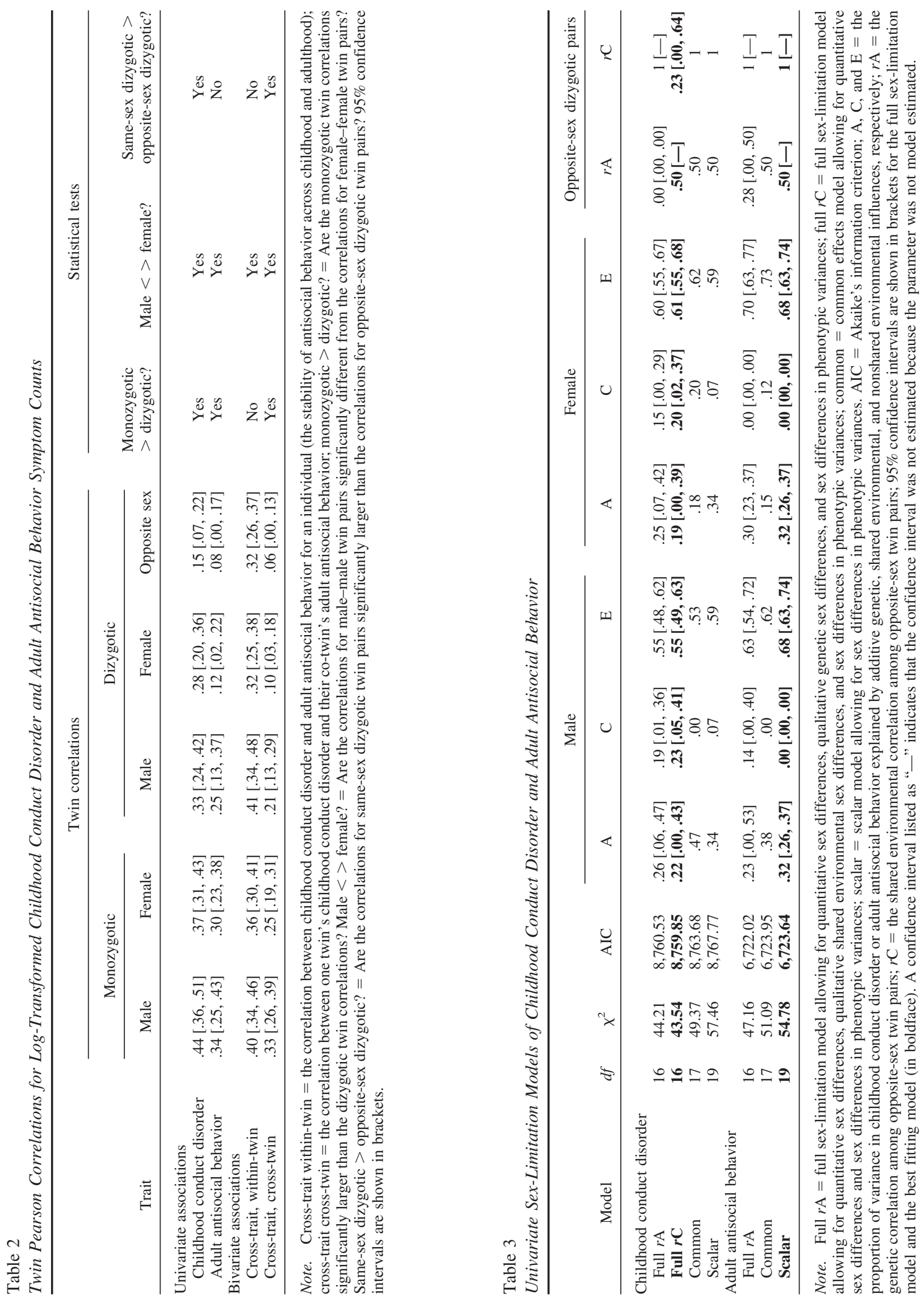


\section{Bivariate Model Results}

Bivariate Cholesky models of childhood conduct disorder and adult antisocial behavior were fit for males and females separately, because the univariate sex-limitation models indicated sex-specific effects on childhood conduct disorder. The standardized path coefficients and $95 \%$ confidence intervals from the full bivariate model are presented in Figure 2 for each sex. The estimates of genetic, shared environmental, and nonshared environmental influences on childhood conduct disorder and adult antisocial behavior from the bivariate models (which can be obtained by squaring the standardized path coefficients) were nearly identical to those obtained from the full univariate sex-limitation models. Slight differences between the univariate and bivariate models can occur because the bivariate models take into account the crosstwin, cross-trait correlations.

Genetic influences common to both childhood conduct disorder and adult antisocial behavior accounted for the majority of the covariation between childhood conduct disorder and adult antisocial behavior for both males and females. For females, the correlation between childhood conduct disorder and adult antisocial behavior was $r=.34$, with genetic, shared environmental, and nonshared environmental influences accounting for $67 \%, 3 \%$, and $30 \%$ of this correlation, respectively. For males, the correlation between childhood conduct disorder and adult antisocial behavior was $r=.41$, with genetic, shared environmental, and nonshared environmental influences accounting for $58 \%, 23 \%$, and $19 \%$ of this correlation, respectively.

\section{Sex Differences and the Equal Environments Assumption}

The equal environments assumption refers to the assumption that monozygotic and dizygotic twins are equally correlated in their exposure to trait-relevant environments. A violation of this assumption could result in inflated estimates of heritability and deflated estimates of the effect of shared environment. Furthermore, a violation of this assumption among one sex but not the other could account for sex differences (or the lack thereof) in the magnitudes of genetic, shared environmental, and nonshared environmental influences. For example, a violation of this assumption among females could artificially inflate heritability estimates for females. This could result in a finding of higher heritability among females than males, or it could increase the heritability of females to be equal to that of males.

We examined sex differences in the veracity of the equal environments assumption in both childhood and adulthood. There was no evidence of a sex by zygosity interaction in predicting similarity of twin childhood environments, $t(2,080)=-0.76, p=.45$, indicating that the difference between monozygotic and dizygotic twins in similarity of childhood environments was not different for males and females. Further, after controlling for zygosity, we found that twin similarity of childhood environment was not related to twin concordance for childhood conduct disorder (scored dichotomously) for females (odds ratio $[\mathrm{OR}]=1.20,95 \%$ confidence interval $[\mathrm{CI}]=1.00,1.44$ ). For males, greater similarity of childhood environment decreased the odds of twin concordance for childhood conduct disorder after controlling for zygosity $(\mathrm{OR}=0.78,95 \% \mathrm{CI}=0.64,0.96)$. Thus, for males there was evidence that the more dissimilar the childhood environment, the greater the likelihood of twin concordance for childhood conduct disorder. Overall, these results suggested that the equal environments assumption was not violated for either sex for childhood conduct disorder.

There was evidence of a significant sex by zygosity interaction in predicting the frequency of adult contact, $b=0.24 ; t(2024)=$ 2.54, $p=.01$. The greater frequency of adult contact among

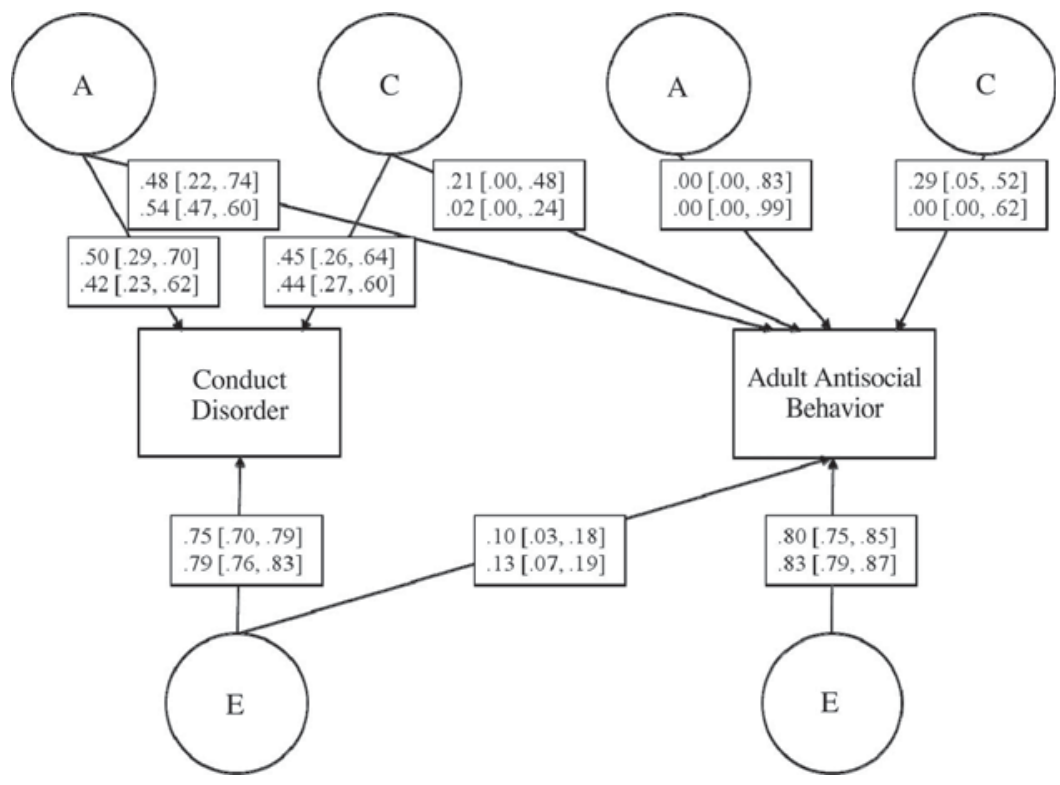

Figure 2. Standardized path coefficients and 95\% confidence intervals for the bivariate twin model of childhood conduct disorder and adult antisocial behavior. $\mathrm{A}=$ additive genetic influences, $\mathrm{C}=$ shared environmental influences, and $\mathrm{E}=$ nonshared environmental influences. Estimates for males are presented in the top rows, and estimates for females are presented in the bottom rows. 
monozygotic compared to dizygotic twins was more apparent for males than females. Further, the frequency of adult contact was related to twin concordance (scored dichotomously) for adult antisocial behavior for females $(\mathrm{OR}=1.22,95 \% \mathrm{CI}=1.05,1.41)$ but not males $(\mathrm{OR}=1.14,95 \% \mathrm{CI}=0.96,1.36)$, although this difference was not significant $(b=-.07, p=.56$ ). Overall, these results could suggest a violation of the equal environments assumption among females. However, a relationship between frequency of adult contact and adult antisocial behavior among females is causally ambiguous-it is as consistent with the interpretation that more adult contact causes female twins to be more alike in their antisocial behavior as the interpretation that similarity in antisocial behavior leads to more frequent contact (Lykken, McGue, Bouchard, \& Tellegen, 1990).

\section{Discussion}

The purpose of this study was to examine sex differences in the genetic, shared environmental, and nonshared environmental influences on antisocial behavior in childhood and adulthood. We found that the genetic or shared environmental factors influencing antisocial behavior were different for males and females in childhood (i.e., a qualitative sex difference) but not in adulthood. Further, genetic and environmental influences accounted for proportionally the same amount of variance in antisocial behavior for males and females in both childhood and adulthood (i.e., no quantitative sex difference). The stability of antisocial behavior from childhood to adulthood was slightly greater for males than females, and genetic factors accounted for the majority of the covariation between childhood conduct disorder and adult antisocial behavior for both sexes. However, familial factors accounted for more of the stability of antisocial behavior for males than females. Finally, the genetic influences on adult antisocial behavior overlapped completely with the genetic influences on childhood conduct disorder for both sexes.

\section{Qualitative Sex Differences}

Reports of qualitative sex differences in the genetic or environmental influences on antisocial behavior are somewhat rare in the extant literature, with only a few twin studies finding evidence of sex-specific genetic or shared environmental effects on antisocial behavior (Derks et al., 2007; Eley et al., 1999; Vierikko et al., 2003; Rose et al., 2004). Part of the reason for the isolated nature of these findings is that relatively few studies have examined qualitative sex differences. Additionally, qualitative sex effects may be small and require large samples and, in particular, large samples of antisocial females, in order to be detected. Thus, some studies reporting null findings may not have had adequate power to detect this type of sex effect. Of the six studies that reported null findings for qualitative sex differences and reported opposite-sex and same-sex twin (or sibling) correlations (Eaves et al., 1997; Jacobson et al., 2002; Saudino et al., 2005; Slutske et al., 1997; Tuvblad et al., 2005; Van Hulle, Rodgers, D’Onofrio, Waldman, \& Lahey, 2007), five reported twin/sibling correlations that were suggestive of sex-specific etiologic influences. In the present study, the correlation for childhood conduct disorder was significantly smaller among opposite-sex twin pairs (.15) than among same-sex female (.28) and male (.33) dizygotic twin pairs, and the correlation for adult antisocial behavior was also smaller (but not significantly) among opposite-sex twin pairs (.08) than among same-sex female (.12) and male (.25) dizygotic twin pairs. In Eaves et al. (1997) the corresponding correlations obtained were .27, .43, and .35; in Saudino et al. (2005) they were .26, .48, and .43 for same-teacher-reported conduct problems, and in Jacobson et al. (2002) they were .21, .34., and .35 for adult antisocial behavior. In addition, Van Hulle et al. (2007) reported that opposite-sex sibling correlations for self-reported aggressive delinquency were smaller than same-sex sibling correlations. Smaller correlations among opposite-sex twin or sibling pairs compared to same-sex pairs suggest that the genetic or shared environmental risk factors for antisocial behavior differ for males and females. If one focuses on effect sizes (i.e., the actual estimates of $r_{\mathrm{A}}$ and $r_{\mathrm{C}}$ derived from comparisons of same-sex and opposite-sex twin correlations) rather than the results of null hypothesis significance tests, the results of the twin and sibling literature on qualitative sex differences are not as inconsistent as they may appear.

In our study, it was difficult to resolve whether the qualitative sex difference observed for childhood conduct disorder was genetic or shared environmental in origin. It should be noted that twin designs are generally not well suited to resolving the source of a qualitative sex difference. Nonetheless, our finding of a smaller correlation among opposite-sex compared to same-sex twin pairs for childhood conduct disorder is clear evidence of factors (whether they are genetic or environmental or both) that are having an impact on one sex but not the other. If sex-specific genetic effects on childhood conduct disorder exist, there are several possible mechanisms by which these sex-specific genetic risk factors could emerge (Prescott, Aggen, \& Kendler, 1999). For example, sex differences in genetic background, geneenvironment interaction, or gene-environment correlation could account for a finding of a qualitative genetic sex difference. An alternative, but not mutually exclusive, explanation is that antisocial behavior is associated with X-linked genes. There is some evidence from molecular genetic studies that antisocial behavior is associated with X-linked genes. A particular variant of the monoamine oxidase A gene, an X-linked gene, appears to confer risk for antisocial behavior, at least in the presence of adverse environmental circumstances (Caspi et al., 2002; Kim-Cohen et al., 2006).

\section{Quantitative Sex Differences}

Genetic, shared environmental, and nonshared environmental influences accounted for proportionally the same amount of variance in antisocial behavior for males and females in both childhood and adulthood. Two other studies examined quantitative sex differences in the genetic and environmental influences on antisocial behavior from childhood to adulthood - one reached a similar conclusion about quantitative sex differences, whereas the other did not. In Hicks et al. (2007), there was no evidence of a quantitative sex difference either in childhood or adulthood. In Jacobson et al. (2002), the heritability was greater for females and shared environmental influences were greater for males in childhood, and no sex differences were apparent in adolescence. In adulthood, though shared environmental influences were small, these influences were greater for males than females. Notably, Jacobson et al. distinguished between child and adolescent antiso- 
cial behavior, whereas Hicks et al. (and the present study) did not, which could account for the differences between studies.

The results of this study highlight another possible explanation for the inconsistent findings across studies regarding quantitative sex differences for antisocial behavior. Table 3 shows that estimates of genetic and environmental influences on antisocial behavior and the difference in these estimates for males and females can change fairly dramatically when qualitative sex differences exist but are not taken into account. For example, had the qualitative genetic or shared environmental sex difference in childhood conduct disorder not been modeled, it might have been concluded that childhood conduct disorder was significantly more heritable for males than females. This suggests that when qualitative sex differences cannot be detected because of low statistical power or just have not been modeled, spurious sex differences in the magnitude of genetic or environmental influences on behavior may emerge.

\section{Changes in the Genetic and Environmental Architecture of Antisocial Behavior Across Development}

Genetic influences on antisocial behavior increased and shared environmental influences decreased from childhood to adulthood for both males and females, consistent with the findings of Lyons et al. (1995) and Jacobson et al. (2002). However, whereas Jacobson et al. (2002) found that the increase in heritability across development was attributable to new genetic influences emerging in adolescence and adulthood, the results from both our study and Lyons et al. suggest that the genetic influences on adult antisocial behavior completely overlap with the genetic influences on childhood antisocial behavior, and the magnitude of genetic influences on antisocial behavior simply increases with age. Jacobson et al.'s intriguing finding of unique genetic influences on antisocial behavior emerging in adulthood still awaits replication. The increasing influence of genes and the decreasing influence of shared environment across development demonstrated across studies could simply reflect an adult's greater control over his or her environment relative to that of a child and therefore may be the outcome of an active genotype-environment correlation.

\section{Limitations}

A limitation of this study is that childhood antisocial behavior was assessed retrospectively. Henry, Moffitt, Caspi, Langley, and Silva (1994) found that when participants were asked to retrospectively report on delinquent acts, they tended to both under- and overreport these acts. However, Henry et al. noted that participants may have been quite accurate in recalling whether they had engaged in a delinquent act-they just did not accurately recall the age at which they began to engage in the behavior. Thus, retrospective recall may not have unduly biased reports of childhood conduct disorder in our study, as participants were not asked to report precise dates for their antisocial acts. Nonetheless, it is possible that there is a genetic component to retrospective recall, which could have resulted in overestimates of the heritability of childhood conduct disorder. However, as Jacobson et al. (2002) noted, if retrospective recall is genetically influenced, then the heritability of antisocial behavior might be expected to increase as the length of the recall time increases. This pattern was not observed in our study, as the heritability of antisocial behavior was greater in adulthood than in childhood. Furthermore, our variance component estimates for childhood conduct disorder closely match the estimates obtained from two population-based studies of child and adolescent self-reported delinquency and conduct disorder (Eaves et al., 1997; Taylor, McGue, \& Iacono, 2000). For the purposes of our study, however, the main threat of retrospective reporting is that sex differences in recall might account for our finding of sex-specific genetic or shared environmental influences on childhood conduct disorder. This is unlikely because the accuracy of retrospective reports of delinquent behavior tend to be similar for males and females (Henry et al., 1994, and the present study).

Another limitation of this study is that the assessment of childhood conduct disorder and adult antisocial behavior did not take into account the considerable heterogeneity in antisocial behavior over the life course. The most accurate understanding of sex differences in antisocial behavior and the sources of this sex difference will come from a study that can take into account the heterogeneous nature of antisocial behavior.

\section{Conclusions}

The risk factors for antisocial behavior differed for males and females in childhood but not in adulthood, and genetic and environmental influences accounted for proportionally the same amount of variance in antisocial behavior for males and females in both childhood and adulthood. The types of risk factors for antisocial behavior that differ among the sexes may be genetic or environmental in origin. If there are sex-specific effects on antisocial behavior, they are likely to be small and may not account for much of the sex difference in the prevalence of antisocial behavior. Nonetheless, our findings of sex-specific effects on child antisocial behavior, combined with the replicated finding of a role for the $\mathrm{X}$-linked monoamine oxidase A gene in the etiology of antisocial behavior, suggests that molecular genetic studies directed toward identifying the genes involved in the development of antisocial behavior may have some success if they focus on the $\mathrm{X}$ chromosome or, at minimum, conduct analyses separately by sex. Developing an understanding of the sources of the sex difference in the prevalence of antisocial behavior is likely to be quite complicated, involving research that takes into account the different developmental trajectories of antisocial behavior as well as the interplay between genes and environment.

\section{References}

American Psychiatric Association. (1994). Diagnostic and statistical manual of mental disorders (4th ed.). Washington, DC: Author.

Anderson, D. A. (1999). The aggregate burden of crime. Journal of Law and Economics, 42, 611-642. doi:10.1086/467436

Bartels, M., Hudziak, J. J., van den Oord, E. J. C. G., van Beijsterveld, C. E. M., Rietveld, M. J. H., \& Boomsma, D. I. (2003). Co-occurrence of aggressive behavior and rule-breaking behavior at age 12: Multi-rater analyses. Behavior Genetics, 33, 607-621. doi:10.1023/A:1025787019702

Bucholz, K. K., Cloninger, C. R., Dinwiddie, S. H., Hesselbrock, V. M., Nurnberger, J. I., Reich, T., . . Schuckit, M. A. (1994). A new, semistructured psychiatric interview for use in genetic linkage studies: A 
report of the reliability of the SSAGA. Journal of Studies on Alcohol, 55, $149-158$.

Caspi, A., McClay, J., Moffitt, T. E., Mill, J., Martin, J., Craig, I. W., . . \& Poulton, R. (2002). Role of genotype in the cycle of violence in maltreated children. Science, 297, 851-854. doi:10.1126/science. 1072290

Compton, W. M., Conway, K. P., Stinson, F. S., Colliver, J. D., \& Grant, B. F. (2005). Prevalence, correlates, and comorbidity of DSM-IV antisocial personality syndromes and alcohol and specific drug use disorders in the United States: Results from the National Epidemiologic Survey on Alcohol and Related Conditions. Journal of Clinical Psychiatry, 66, 677-685. doi:10.4088/JCP.v66n0602

Derks, E. M., Dolan, C. V., Hudziak, J. J., Neale, M. C., \& Boomsma, D. I. (2007). Assessment and etiology of attention deficit hyperactivity disorder and oppositional defiant disorder in boys and girls. Behavior Genetics, 37, 559-566. doi:10.1007/s10519-007-9153-4

Eaves, L. J., Eysenck, H. J., \& Martin, N. G. (1989). Genes, culture, and personality: An empirical approach. New York, NY: Academic Press.

Eaves, L. J., Silberg, J. L., Meyer, J. M., Maes, H. H., Simonoff, E., Pickles, A., Rutter, M., ... \& Hewitt, J. K. (1997). Genetics and developmental psychopathology: 2. The main effects of genes and environment on behavioral problems in the Virginia Twin Study of Adolescent Behavioral Development. Journal of Child Psychology and Psychiatry, 38, 965-980. doi:10.1111/j.1469-7610.1997.tb01614.x

Eley, T. C., Lichtenstein, P., \& Stevenson, J. (1999). Sex differences in the etiology of aggressive and nonaggressive antisocial behavior: Results from two twin studies. Child Development, 70, 155-168. doi:10.1111/ 1467-8624.00012

Gelhorn, H. L., Stallings, M. C., Young, S. E., Corley, R. P., Rhee, S. H., \& Hewitt, J. K. (2005). Genetic and environmental influences on conduct disorder: Symptom, domain and full-scale analyses. Journal of Child Psychology and Psychiatry, 46, 580-591. doi:10.1111/j.14697610.2004.00373.x

Henry, B., Moffitt, T. E., Caspi, A., Langley, J., \& Silva, P. A. (1994). On the "remembrance of things past": A longitudinal evaluation of the retrospective method. Psychological Assessment, 6, 92-101. doi: 10.1037/1040-3590.6.2.92

Hicks, B. M., Blonigen, D. M., Kramer, M. D., Krueger, R. F., Patrick, C. J., Iacono, W. G., \& McGue, M. (2007). Gender differences and developmental change in externalizing disorders from late adolescence to early adulthood: A longitudinal twin study. Journal of Abnormal Psychology, 116, 433-447. doi:10.1037/0021-843X.116.3.433

Jacobson, K. C., Prescott, C. A., \& Kendler, K. S. (2002). Sex differences in the genetic and environmental influences on the development of antisocial behavior. Development and Psychopathology, 14, 395-416. doi:10.1017/S0954579402002110

Kendler, K. S., \& Prescott, C. A. (2006). Genes, environment, and psychopathology: Understanding the causes of psychiatric and substance use disorders. Boston, MA: Guilford Press.

Kim-Cohen, J., Caspi, A., Taylor, A., Williams, B., Newcombe, R., Craig, I. W., \& Moffitt, T. E. (2006). MAOA, maltreatment, and geneenvironment interaction predicting children's mental health: New evidence and a meta-analysis. Molecular Psychiatry, 11, 903-913. doi: 10.1038/sj.mp.4001851

Lykken, D. T., McGue, M., Bouchard, T. J., \& Tellegen, A. (1990). Does contact lead to similarity or similarity to contact? Behavior Genetics, 20, 547-561. doi:10.1007/BF01065871

Lynskey, M. T., Heath, A. C., Nelson, E. C., Bucholz, K. K., Madden, P. A. F., Slutske, W. S., . . \& Martin, N. G. (2002). Genetic and environmental contributions to cannabis dependence in a national young adult twin sample. Psychological Medicine, 32, 195-207. doi:10.1017/ S0033291701005062

Lyons, M. J., True, W. R., Eisen, S. A., Goldberg, J., Meyer, J. M., Faraone, S. F., Eaves, L. J., \& Tsuang, M. T. (1995). Differential heritability of adult and juvenile antisocial traits. Archives of General Psychiatry, 52, 906-915.

Miles, D. R., \& Carey, G. (1997). Genetic and environmental architecture of human aggression. Journal of Personality and Social Psychology, 72, 207-217. doi:10.1037/0022-3514.72.1.207

Moffitt, T. E., Caspi, A., Rutter, M., \& Silva, P. A. (2001). Sex differences in antisocial behavior: Conduct disorder, delinquency, and violence in the Dunedin Longitudinal Study. New York, NY: Cambridge University Press. doi:10.1017/CBO9780511490057

Muthén, L. K., \& Muthén, B. O. (1998-2007). Mplus user's guide (5th ed.). Los Angeles, CA: Muthén \& Muthén.

Neale, M. C., \& Cardon, L. R. (1992). Methodology for genetic studies of twins and families. Boston, MA: Kluwer Academic.

Prescott, C. A., Aggen, S. H., \& Kendler, K. S. (1999). Sex differences in the sources of genetic liability to alcohol abuse and dependence in a population-based sample of U.S. twins. Alcoholism: Clinical and Experimental Research, 23, 1136-1144. doi:10.1111/j.15300277.1999.tb04270.x

Rhee, S. H., \& Waldman, I. D. (2002). Genetic and environmental influences on antisocial behavior: A meta-analysis of twin and adoption studies. Psychological Bulletin, 128, 490-529. doi:10.1037/00332909.128.3.490

Rijsdijk, F. V., \& Sham, P. C. (2002). Analytic approaches to twin data using structural equation models. Briefings in Bioinformatics, 3, 119133. doi:10.1093/bib/3.2.119

Rose, R. J., Dick, D. M., Viken, R. J., Pulkkinen, L., \& Kaprio, J. (2004), Genetic and environmental effects on conduct disorder and alcohol dependence symptoms and their covariation at age 14. Alcoholism: Clinical and Experimental Research, 28, 1541-1548. doi:10.1097/ 01.ALC.0000141822.36776.55

Rowe, D. C., Vazsonyi, A. T., \& Flannery, D. J. (1995). Sex differences in crime: Do means and within-sex variation have similar causes? Journal of Research in Crime and Delinquency, 32, 84-100. doi:10.1177/ 0022427895032001004

Rutter, M., Caspi, A., \& Moffitt, T. E. (2003). Using sex differences in psychopathology to study causal mechanisms: Unifying issues and research strategies. Journal of Child Psychology and Psychiatry, 44, 1092-1115. doi:10.1111/1469-7610.00194

Saudino, K. J., Ronald, A., \& Plomin, R. (2005). The etiology of behavior problems in 7-year-old twins: Substantial genetic influence and negligible shared environmental influence for parent ratings and ratings by same and different teachers. Journal of Abnormal Child Psychology, 33, 113-130. doi:10.1007/s10802-005-0939-7

Silberg, J. L., Erickson, M. T., Meyer, J. M., Eaves, L. J., Rutter, M. L., \& Hewitt, J. K. (1994). The application of structural equation modeling to maternal ratings of twins' behavioral and emotional problems. Journal of Consulting and Clinical Psychology, 62, 510-521.

Slutske, W. S., Heath, A. C., Dinwiddie, S. H., Madden, P. A. F., Bucholz, K. K., Dunne, M. P., Statham, D. J., \& Martin, N. G. (1997). Modeling genetic and environmental influences on the etiology of conduct disorder: A study of 2,682 adult twin pairs. Journal of Abnormal Psychology, 106, 266-279. doi:10.1037/0021-843X.106.2.266

Slutske, W. S., Meier, M. H., Zhu, G., Statham, D. J., Blaszczynski, A., \& Martin, N. G. (2009). The Australia Twin Study of Gambling (OZ-GAM): Rationale, sample description, predictors of participation, and a first look at sources of individual differences in gambling involvement. Twin Research and Human Genetics, 12, 63-78. doi:10.1375/ twin.12.1.63

Stevenson, J., \& Graham, P. (1988). Behavioral deviance in 13-year-old twins: An item analysis. Journal of the American Academy of Child and Adolescent Psychiatry, 27, 791-797. doi:10.1097/00004583198811000-00023

Taylor, J., McGue, M., \& Iacono, W. G. (2000). Sex differences, assortative mating, and cultural transmission effects on adolescent delinquency: 
A twin family study. Journal of Child Psychology and Psychiatry, 41, 433-440. doi:10.1111/1469-7610.00628

Tuvblad, C., Eley, T. C., \& Lichtenstein, P. (2005). The development of antisocial behavior from childhood to adolescence. A longitudinal twin study. European Child and Adolescent Psychiatry, 14, 216-225. doi: 10.1007/s00787-005-0458-7

van den Oord, E. J. C. G., Boomsma, D. I., \& Verhulst, F. C. (1994). A study of problem behaviors in 10- to 15-year-old biologically related and unrelated international adoptees. Behavior Genetics, 24, 193-205. doi: 10.1007/BF01067187

Van Hulle, C. A., Rodgers, J. L., D’Onofrio, B. M., Waldman, I. D., \&
Lahey, B. B. (2007). Sex differences in the causes of self-reported adolescent delinquency. Journal of Abnormal Psychology, 116, 236248. doi:10.1037/0021-843X.116.2.236

Vierikko, E., Pulkkinen, L., Kaprio, J., Viken, R., \& Rose, R. J. (2003). Sex differences in genetic and environmental effects on aggression. Aggressive Behavior, 29, 55-68. doi:10.1002/ab.10038

Received February 21, 2010

Revision received October 4, 2010

Accepted October 11, 2010

\section{Call for Papers: Journal of Consulting and Clinical Psychology Special Issue on Behavioral Medicine and Clinical Health Psychology}

The Journal of Consulting and Clinical Psychology plans to publish a special issue on "Behavioral Medicine and Clinical Health Psychology" in 2012. As such, we are calling for original manuscript submissions within this broad area. Such a special issue will be the fourth that JCCP has published in behavioral medicine over the last four decades. Past issues have proven to be a seminal resource for researchers, practitioners, and policymakers interested in the relationships among behavior, psychological science, and health. Empirical, review (descriptive or quantitative), or novel conceptual or methodological contributions related to the association between clinical and behavioral science and the development and course of disease or the promotion of health are welcomed. Updated or innovative examinations of topics addressed in previous JCCP behavioral medicine and clinical health psychology special issues (e.g., interventions targeting behavioral risk factors for disease, behavioral management of chronic conditions) are welcomed, as are examinations of recently emerging topics (e.g., technology and behavioral medicine, implications of behavioral and psychological science for the clinical translation of genomic methods). Papers addressing behavioral medicine and clinical health psychology topics as part of a broader biopsychosocial or ecological systems perspective are also welcomed. Articles addressing issues of diversity in behavioral medicine (e.g., RCTs of culturally-sensitive psychosocial interventions, diversity-related health care disparities) are especially sought.

The editors for this issue are Alan J. Christensen (Guest Editor) and Arthur M. Nezu (JCCP Editor). Authors interested in having a manuscript considered for this special issue need to first submit a 1-page proposal outlining the full manuscript by July 1, 2011. Authors of selected proposals will be notified inviting them to submit a full paper due September 30, 2011. All such papers will undergo normal peer review evaluations. Note that an initial invitation does not signify eventual acceptance. All manuscripts should be prepared in strict accordance with JCCP guidelines (please refer to the website: http://www.apa.org/pubs/journals/ccp/) and eventually submitted through the standard JCCP portal. Questions about appropriate topics, as well as the 1-page proposals, can be sent to either Alan Christensen (alan-christensen@uiowa.edu) or Art Nezu (amn23@drexel.edu). 